\title{
Modelización, argumentación
} $y$ transferencia de conocimiento sobre el sistema inmunológico a partir de una controversia sobre vacunación en futuros docentes

\author{
Modeling, argumentation and knowledge transfer \\ of preservice teachers about the immune system \\ on a controversy about vaccination
}

Gurutze Maguregi González, Araitz Uskola Ibarluzea

Departamento de Didáctica de la Matemática y las Ciencias Experimentales.

Universidad del País Vascol Euskal Herriko Unibertsitatea- UPVIEHU

gurutze.maguregi@ehu.eus, araitz.uskola@ehu.eus
Begońa Burgoa Etxaburu

ISEI-IVEI (Instituto de Evaluación e Investigación Educativa); grupo LIEC (UAB)

bbetxaburu@gmail.com

RESUMEN • En este trabajo se analiza la construcción del modelo de sistema inmunológico incluido en el modelo de ser vivo. Se ha utilizado una controversia sociocientífica sobre la vacunación, sobre la que 42 estudiantes del Grado de Educación Primaria han tenido que buscar información y utilizarla para tomar decisiones, construir conocimiento y transferirlo. Se han analizado las producciones escritas y las discusiones. Los resultados muestran que la competencia argumentativa mejora, tanto en número como en variedad de justificaciones. Se observan indicios de construcción del modelo de sistema inmunológico, ya que se hace referencia a elementos de su estructura, intercambio de materia y cambios producidos, especialmente en lo referente a las vacunas. Sin embargo, tienen dificultades en la transferencia de conocimiento cuando esta es lejana.

PALABRAS CLAVE: argumentación; controversias sociocientíficas; modelización; sistema inmunológico; transferencia.

ABSTRACT - In this article we analyze the construction of the model of immune system, which is included in the model of living beings. 42 Elementary Preservice teachers took part in a teaching sequence based on a socioscientific controversy about vaccination. They searched for information, made decisions, constructed knowledge and transferred it. The written productions and oral discussions of the students have been analyzed. The results show that the ability for argumentation improves both in number and variety of justifications. There is evidence of the construction of the model of immune system, such as references to constituents of its structure, matter interchange and the resultant changes, specially with respect to vaccines. However, difficulties in transfer of knowledge are observed when it is far transfer.

KEYWORDS: argumentation; socio-scientific issues; modeling; immune system, transfer.

Recepción: noviembre 2016• Aceptación: marzo 2017• Publicación: junio 2017 


\section{INTRODUCCIÓN}

En la sociedad actual se presentan temas relacionados con el medio ambiente, el consumo o la salud, sobre los que diversos agentes sociales manifiestan posturas diferenciadas (Díaz y Jiménez-Liso, 2012). Esto hace necesaria la capacitación de la ciudadanía para que pueda participar de manera activa en la toma de las decisiones, manteniendo una actitud crítica y responsable, siendo esta una de las finalidades de la educación científica (BOE, 2014).

Sin embargo, diversos informes ponen de manifiesto la falta de ciudadanos y ciudadanas mínimamente formados en ciencias y, ya que la alfabetización científica de esa ciudadanía queda en manos, entre otros, del profesorado de educación primaria, su formación es de vital importancia para el logro de ese objetivo (COSCE, 2011).

Así, el Informe ENCIENDE (Jiménez-Aleixandre, Sanmartí y Couso 2011) recomienda la necesidad de un replanteamiento de la formación del profesorado de ciencias en cuanto a los contenidos que se deben trabajar y la metodología, más acorde con la demanda de capacitación de la sociedad actual. De esta manera se deberían incluir actividades y tareas que demanden del alumnado la aplicación de los conocimientos adquiridos y que ese conocimiento esté relacionado con su contexto social para que sea percibido como relevante para su vida, lo que puede contribuir a la motivación e interés hacia las ciencias.

Uno de los temas que en la actualidad provoca diferentes posicionamientos en la sociedad es la vacunación, por lo que puede ser utilizado como contexto cercano del alumnado para trabajar el modelo de ser vivo desde la perspectiva del funcionamiento del sistema inmunológico.

Una de las medidas de mayor impacto en cuestión de salud pública durante el siglo xx ha sido la vacunación, que ha conseguido erradicar a nivel mundial algunas enfermedades, disminuir su número y también la mortalidad por enfermedades infecciosas (MSSSI, 2016). Todo esto ha sido posible gracias a la puesta en marcha de programas sistemáticos de vacunación infantil, como el implantado en España en 1975, que se modifica anualmente según los cambios epidemiológicos.

El proceso de vacunación se basa en inocular una vacuna a una persona o animal para provocar una respuesta de defensa y preservarlos de una enfermedad determinada, siendo la vacuna un preparado de antígenos que, aplicado a un organismo, produce en él una respuesta de defensa.

Sin embargo, a pesar de que los avances a nivel de salud pública son evidentes, la situación epidemiológica puede variar por diversos motivos. Por un lado, los países en vías de desarrollo ven limitado su acceso a las vacunas debido a su precio y, por otro lado, el incremento de la desconfianza y el rechazo hacia las vacunas, que algunas personas perciben como inseguras e innecesarias, sobre todo en los países desarrollados (McIntosh, Janda, Ehrich, Pettoello-Mantovani y Somekh, 2016). Ante esta última situación, la Unión Europea de Sociedades Pediátricas ha publicado un Pronunciamiento Europeo contra el Rechazo a las Vacunas (AEP, 2016).

El fallecimiento de un niño de seis años enfermo de difteria durante el verano de 2015 , que no había sido vacunado por expreso deseo de sus padres (Mouzo, 2015), motivó al equipo investigador a abordar la controversia existente en la actualidad ante la vacunación.

\section{MARCO TEÓRICO}

\section{Controversias sociocientíficas}

Se consideran controversias sociocientíficas los dilemas o cuestiones que se plantean en la sociedad, relacionadas o basadas en cuestiones científicas y en las que están implicadas cuestiones éticas, sociales, económicas, ambientales y políticas, que tienen relevancia para la vida de las personas (Sadler y Zeidler, 
2005). Además, sobre dichas cuestiones existen discrepancias tanto en la sociedad como en la comunidad científica (Díaz y Jiménez-Liso, 2012).

La utilización de controversias sociocientíficas en el aula de ciencias promueve el desarrollo de la competencia científica ya que persigue, por un lado, la construcción de conocimiento sobre el tema que se trata y, por otro, el desarrollo de la argumentación y la toma de decisiones ante las situaciones planteadas (Jiménez-Aleixandre, 2010).

Son numerosas las investigaciones sobre diferentes controversias sociocientíficas trabajadas en el aula (Díaz y Jiménez-Liso, 2012), algunas de ellas relacionadas con temas de salud. Aunque son escasas las que abordan el estudio del sistema inmunológico, cabe destacar la de Aznar y Puig (2016a, 2016b), sobre las concepciones y modelos del profesorado de primaria en formación sobre la tuberculosis, y la que analiza los aspectos que tienen en cuenta un grupo de adolescentes para tomar la decisión de vacunarse o no (Lundström, Ekborg, y Ideland, 2012).

En el estudio de Aznar y Puig (2016a,2016b) se analizan las concepciones que sobre la tuberculosis tienen dos grupos de futuros profesores de educación primaria, uno de ellos afectado por la enfermedad. Los resultados obtenidos muestran que el grupo afectado tiene un mayor conocimiento sobre la enfermedad. Ambos grupos mejoran en la comprensión y utilización adecuada de términos como linfocito o vacuna, esta última entendida inicialmente como agente curativo y no preventivo. Como conclusión general apuntan que las ideas que representa el alumnado todavía están distantes de la del modelo científico de referencia.

La investigación planteada por Lundström et al. (2012) facilita, a través de la controversia científica de la vacunación, desarrollar la argumentación y la toma de decisiones. Los autores analizan qué aspectos tienen en cuenta siete adolescentes entre 17 y 19 ańos para tomar la decisión de vacunarse contra la gripe. Así, en la justificación de sus decisiones, valoran en mayor medida los efectos secundarios frente a los riesgos de contraer la enfermedad, tanto los que están a favor como el que está en contra.

\section{Modelización. El modelo de sistema inmunológico en relación con el modelo de ser vivo}

Hoy día, la enseñanza de modelos científicos se considera como uno de los ejes centrales en el aprendizaje del conocimiento científico y la modelización, como el principal proceso para construirlos y utilizarlos (Merino, Felipe y Gallarreta, 2005).

Schwarz et al. (2009) definen como modelo aquella representación abstracta y simplificada de un sistema que se centra en sus características centrales y que sirve para explicar y predecir fenómenos científicos. El proceso de modelización, es decir, el proceso de construcción de modelos mentales, se genera mediante los razonamientos y experiencias que se lleven a cabo (Justi, 2006) y es señalado como clave en el aprendizaje de las ciencias en la escuela. Además, la práctica de modelización en el aula permite a los docentes acceder a las ideas del alumnado y conocer cómo evolucionan a través de la comunicación de sus modelos mentales (Mendonça y Justi 2014).

El modelo de ser vivo es considerado tanto desde las ciencias como desde la ciencia escolar como uno de los grandes modelos que construir. En la figura 1 se muestra un modo de representar la visión sistémica en la ciencia escolar, a partir de la cual afrontar el estudio del modelo de ser vivo (Pigrau y Sanmartí, 2015). En ella se recogen ideas clave comunes que están en la base de la construcción del modelo de ser vivo: a) los límites arbitrarios que especifican qué hay fuera del sistema (alrededor) y qué hay y qué pasa dentro; $b$ ) una estructura determinada por los elementos que lo forman y sus interrelaciones; c) los cambios producidos, y d) los intercambios de energía, materia e información con su entorno. 


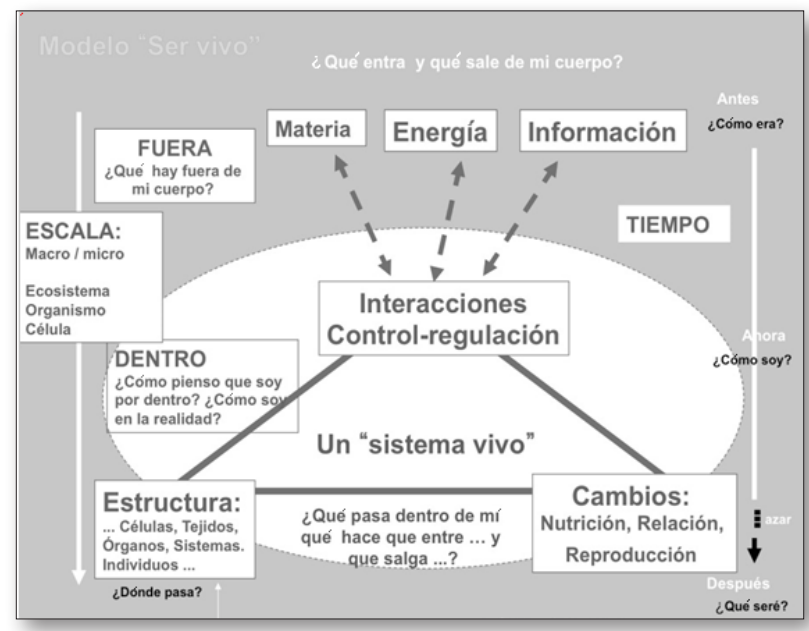

Fig. 1. Modelo de ser vivo (Pigrau y Sanmartí, 2015).

El sistema inmunológico comprende órganos, tejidos, células y moléculas responsables de la inmunidad, que actúan de modo colectivo, cooperativo y coordinado; además, sus componentes celulares transitan por la sangre, linfa y otros tejidos. La construcción del modelo de sistema inmunológico a través del contexto de vacunación supone un acercamiento al gran modelo de ser vivo de acuerdo con la visión sistémica actual. El conocimiento sobre el sistema inmunológico proporciona explicaciones sobre distintos fenómenos que se producen en el cuerpo para mantener su equilibrio en relación con su entorno y consigo mismo (véase figura 2). Las dificultades de comprensión de los estudiantes sobre el funcionamiento del sistema inmunológico han sido analizadas en la investigación realizada por Andrade, Araújo-Jorge y Coutinho-Silva (2016) con 71 estudiantes. Hallaron que la mayoría de los estudiantes atribuían al sistema inmunológico acciones de ataque y defensa destinadas a la protección del organismo ante la invasión de patógenos y cuerpos extrańos. Así, consideraban a los microorganismos como enemigos que deben ser vencidos por los linfocitos, anticuerpos y fagocitos. Se verificó un limitado conocimiento de la fisiología del sistema inmunológico respecto a la dinámica de interacciones del organismo consigo mismo y con los elementos del entorno para la consecución del equilibrio.

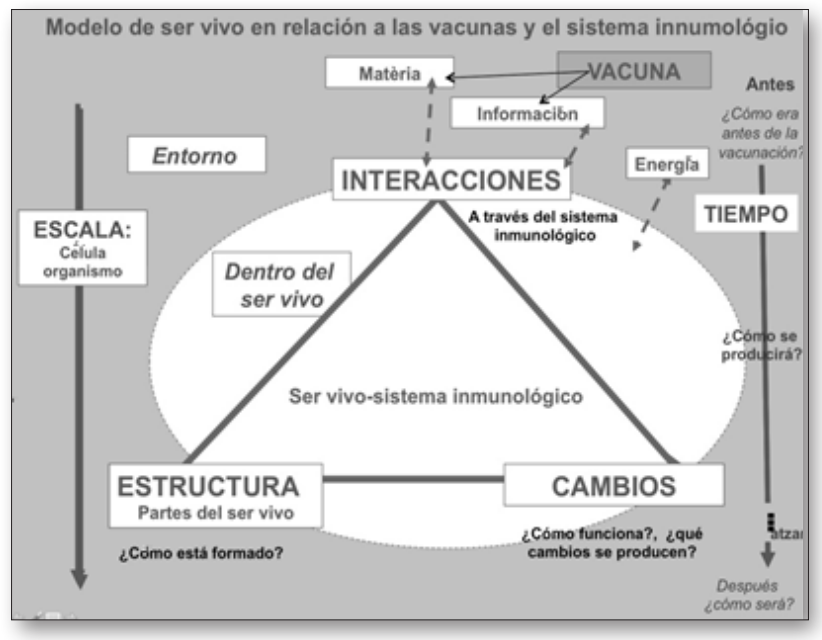

Fig. 2. Modelo de ser vivo en relación con el sistema inmunológico (elaboración propia). 
El modelo de sistema inmunológico propuesto pretende avanzar de las concepciones más beligerantes, mayoritario desde 1960, hacia aquel que se centre en el papel de este como restaurador del equilibrio perdido y/o mantenimiento de la estructura y el equilibrio del cuerpo (Andrade et al., 2016). Así, en esta investigación, la modelización se lleva a cabo a partir de diversos contextos.

Un aspecto básico del proceso de modelización es la experimentación orientada a la introducción de nuevas maneras de mirar y a la identificación de pruebas que posibiliten la evaluación, revisión y evolución del propio modelo. Así, tanto la investigación en didáctica como los nuevos marcos curriculares de ciencias señalan que la construcción de modelos y su aplicación deben estar centradas en la participación del alumnado en las prácticas científicas (Schwarz et al., 2009). En este sentido Jiménez-Aleixandre (2012) habla de correspondencia entre las prácticas científicas de indagación, modelización y argumentación con el currículum de ciencias. De esta manera, el aprendizaje del modelo inmunológico permite la construcción de conocimientos que pueden ayudar al estudiante en la toma de decisiones y opciones relacionadas con la salud.

La estrategia de enseñanza basada en modelos se fundamenta en la concepción de estos como núcleo central de conocimiento científico, y la modelización como principal proceso para construir y utilizar ese conocimiento. Ello significa que el estudiante competente aplicará dicho modelo durante la transferencia a una nueva situación contextualizada.

\section{¿Qué se entiende por transferencia?}

El concepto de transferencia ha sido acuñado para designar la utilización del conocimiento adquirido en un contexto específico a una nueva situación. Aunque la psicología lleva estudiando el proceso de transferencia más de un siglo, en el mundo educativo adquiere importancia a partir de la década de los setenta del siglo pasado, cuando se evidencia que el cómo aprendemos está estrechamente relacionado con el cómo utilizamos lo aprendido (Goldstone y Day, 2012). Desde la perspectiva Actor Oriented Transfer-AOT (Lobato, 2012), tenida en cuenta para esta investigación, se conceptualiza la transferencia no solo como la aplicación del modelo mental que una persona lleve a cabo (aplicación estática del conocimiento), sino como la reconstrucción dinámica del conocimiento aprendido que la persona realiza en la nueva situación (Roorda, Vos y Goedhart, 2015). Por ello, para su análisis, son cruciales los razonamientos expuestos por el alumnado, y no solo lo acertado de las respuestas.

Son abundantes las clasificaciones en torno a la transferencia; en esta investigación se ha tenido en cuenta la de Barnett y Ceci (2002). En función del periodo transcurrido desde la situación de aprendizaje y de la similitud en las tareas propuestas se diferencia entre transferencia cercana, cuando la nueva situación se encuentra próxima a la de aprendizaje o bien es similar a ella, y transferencia lejana, en caso contrario.

\section{Toma de decisión argumentada}

Los contextos sociocientíficos pueden facilitar que el alumnado construya y transfiera conocimiento, y también que construya argumentos, que defienda su posición y critique justificadamente la de otros (Jiménez-Aleixandre, 2010).

Hay varias formas de evaluar la calidad de la argumentación, dependiendo del contexto en el que se produce. Cuando se trata de cuestiones sociocientíficas en las que se toma una decisión justificada, uno de los aspectos clave es la capacidad de construir un contraargumento, lo que implica construir refutaciones (Erduran, Simon y Osborne, 2004). Otro de los criterios que determinan la calidad argumentativa es la capacidad de pensar en otra perspectiva, en las limitaciones de la propia opción o las ventajas de las otras (Kortland, 1996). Es por eso interesante que, al igual que en las situaciones reales, 
las opciones presenten ventajas y desventajas, de tal forma que en la decisión final, además de tenerlas en cuenta, el alumnado establezca una jerarquía de valores (Jiménez-Aleixandre, 2010). Así lo hicieron Felton, García-Milá y Gilabert (2009), que observaron en su estudio que los argumentos posteriores a la discusión en parejas eran de mayor calidad que los escritos anteriormente y mejoraban especialmente a la hora de justificar la opción escogida y de reconocer las limitaciones de la propia opción, aspecto que incluyeron en las refutaciones (García-Milá, Gilabert, Erduran y Felton, 2013).

\section{OBJETIVOS}

El objetivo general de la investigación es el análisis de la construcción del modelo de ser vivo a través de la comprensión del sistema inmunológico, de los estudiantes del Grado de Educación Primaria, mediante la controversia sociocientífica referente a la vacunación. Las preguntas de la investigación son:

- ¿Qué modelo de sistema inmunológico construyen en el contexto de la vacunación y cómo lo transfieren a otros contextos?

- ¿Cómo desarrollan la competencia argumentativa en cuanto al uso de ventajas y desventajas de la vacunación en la toma de decisión?

\section{METODOLOGÍA}

La investigación se ha realizado en una clase de cuarto curso del Grado de Educación Primaria en el primer semestre del curso 2015/16. Para ello, el equipo formado por las tres autoras diseñó una secuencia de actividades en torno a la vacunación, que fue implementada por una de ellas. A lo largo de las actividades, se recogieron los trabajos escritos por los estudiantes y se grabaron en audio las discusiones de los grupos en una de las actividades. Para responder a las preguntas de la investigación, se ha seguido una metodología interpretativa (Erickson, 1989) y se ha procedido en varias fases. En el caso de la segunda pregunta, la componente interpretativa es menos difusa, por lo que, tras realizar un análisis de una cuarta parte de la muestra de forma conjunta entre las tres autoras, el resto de la muestra se ha dividido y analizado de forma independiente y, finalmente, se han puesto en común todos los resultados, llegando a acuerdos en los casos de falta de consenso. Sin embargo, la interpretación para la categorización de respuestas referidas a la primera pregunta es más delicada, por lo que las tres investigadoras han realizado el análisis de la muestra completa de forma independiente para su validación (Gee, 1999). Los disensos han sido escasos (en torno al $15 \%$ ) y han sido superados mediante debates.

\section{Participantes}

Los participantes fueron 42 estudiantes en total (21,7 años de media, 85,7 \% chicas), de cuarto curso del Grado de Educación Primaria, que cursaban la asignatura «Nuevas tendencias en la didáctica de las ciencias». La secuencia se implementó en octubre-diciembre de 2015 y el número de estudiantes varió en cada sesión (tabla 1). Se dedicaron un total de 6,5 horas de clase a las actividades. Para las actividades grupales se formaron 9 grupos con 4-5 miembros. Los nombres de los estudiantes se han sustituido por pseudónimos con la forma $\mathrm{nGAx}$ o $\mathrm{nGOx}$, en los que el primer número indica el grupo al que pertenecen, se utiliza $\mathrm{A}$ (chicas) u $\mathrm{O}$ (chicos) y x un número.

\section{Secuencia de actividades}

La secuencia de actividades está detallada en la tabla 1. En primer lugar, se procedió a preguntar a los estudiantes individualmente acerca de sus conocimientos sobre el sistema inmunológico y la 
vacunación, y su posicionamiento frente a esta última. Primero individualmente y luego en grupo, formularon interrogantes acerca del tema que les ayudarían a resolver las dudas surgidas. Para que la formulación de preguntas cubriera los objetivos de aprendizaje preestablecidos por el equipo (OA1: Comprender el funcionamiento del sistema inmunológico; OA2: Conocer en qué consisten los diferentes tipos de vacunas; OA3: Comprender el proceso de vacunación en el cuerpo humano; OA4: Conocer las ventajas y las desventajas de las vacunas), se analizaron las preguntas formuladas el primer día y se seleccionaron dos noticias de prensa que ayudaran a ampliar los interrogantes. Las noticias de prensa constituyen un buen recurso como punto de partida para promover el aprendizaje y debate sobre temas sociocientíficos (McClune y Jarman, 2014). Se adoptó, de esta manera, un enfoque similar al utilizado en el aprendizaje basado en problemas (Hmelo-Silver y Barrows, 2008), que consta de tres fases: análisis del problema, aprendizaje autodirigido y colaborativo y presentación de informes. Así, los estudiantes procedieron al planteamiento de preguntas y a la búsqueda y puesta en común de la información. Tras ello, se les plantearon varias actividades en las que utilizar lo aprendido, algunas de las cuales consistían en dar una explicación utilizando el conocimiento científico y otras en las que, como parte del profesorado o de la ciudadanía, tenían que tomar una decisión justificada relacionada con la vacunación. Las tomas de decisión, especialmente las grupales, suponen una actividad adecuada para justificar las opiniones propias, por lo que pueden favorecer la argumentación (Jiménez-Aleixandre, 2010).

Tabla 1.

Secuencia de actividades en torno a la vacunación. Se indican los objetivos de la secuencia y qué actividades (y, entre paréntesis, qué preguntas en el caso de cuestionarios con varias preguntas) se han utilizado para los objetivos de la investigación (el primer objetivo de investigación se ha dividido en tres partes: VAC, conocimiento acerca de las vacunas; SIVAC, conocimiento acerca del sistema inmunológico en el contexto de la vacunación, SICON, conocimiento acerca del sistema inmunológico en otros contextos)

\begin{tabular}{|c|c|c|c|c|c|c|c|}
\hline \multirow{3}{*}{ Semana } & \multirow{3}{*}{$\mathrm{N}$} & \multirow{3}{*}{$\begin{array}{l}\text { Objetivos } \\
\text { de la secuencia }\end{array}$} & \multirow{3}{*}{ Actividades } & \multicolumn{4}{|c|}{ Objetivos de la investigación } \\
\hline & & & & \multicolumn{3}{|c|}{ 1. Modelo de SI } & \multirow{2}{*}{$\begin{array}{l}\text { 2. Competencia } \\
\text { argumentativa }\end{array}$} \\
\hline & & & & VAC & SIVAC & SICON & \\
\hline \multirow[t]{3}{*}{1} & \multirow[t]{3}{*}{42} & $\begin{array}{l}\text { Expresar } \\
\text { conocimientos y } \\
\text { opiniones }\end{array}$ & Cuestionario 1 & $\begin{array}{c}x \\
(3,5,6,7,8)\end{array}$ & $\begin{array}{c}\mathrm{x} \\
(4)\end{array}$ & $\begin{array}{c}\mathrm{x} \\
(1,2)\end{array}$ & $\begin{array}{c}x \\
(11)\end{array}$ \\
\hline & & $\begin{array}{l}\text { Intercambiar } \\
\text { opiniones sobre las } \\
\text { vacunas }\end{array}$ & Discusión 1 & & & & \\
\hline & & $\begin{array}{l}\text { Formular preguntas } \\
\text { que orienten } \\
\text { la búsqueda de } \\
\text { información }\end{array}$ & $\begin{array}{l}\text { Planteamiento de } \\
\text { preguntas } 1\end{array}$ & & & & \\
\hline \multirow[t]{2}{*}{2} & \multirow[t]{2}{*}{41} & $\begin{array}{l}\text { Leer y debatir acerca } \\
\text { de dos artículos de } \\
\text { prensa }\end{array}$ & $\begin{array}{l}\text { Lectura de artícu- } \\
\text { los de prensa }\end{array}$ & & & & \\
\hline & & $\begin{array}{l}\text { Ampliar la } \\
\text { formulación de } \\
\text { preguntas y distribuir } \\
\text { tareas }\end{array}$ & $\begin{array}{l}\text { Planteamiento de } \\
\text { preguntas } 2\end{array}$ & & & & \\
\hline
\end{tabular}




\begin{tabular}{|c|c|c|c|c|c|c|c|}
\hline \multirow{3}{*}{ Semana } & \multirow{3}{*}{$\mathrm{N}$} & \multirow{3}{*}{$\begin{array}{l}\text { Objetivos } \\
\text { de la secuencia }\end{array}$} & \multirow{3}{*}{ Actividades } & \multicolumn{4}{|c|}{ Objetivos de la investigación } \\
\hline & & & & \multicolumn{3}{|c|}{ 1. Modelo de SI } & \multirow{2}{*}{$\begin{array}{l}\text { 2. Competencia } \\
\text { argumentativa }\end{array}$} \\
\hline & & & & VAC & SIVAC & SICON & \\
\hline \begin{tabular}{|l}
$2-4$ \\
(fuera \\
de clase)
\end{tabular} & & $\begin{array}{l}\text { Buscar información } \\
\text { acerca de los } \\
\text { interrogantes }\end{array}$ & $\begin{array}{l}\text { Búsqueda de } \\
\text { información }\end{array}$ & & & & \\
\hline \multirow[t]{2}{*}{4} & \multirow[t]{2}{*}{41} & $\begin{array}{l}\text { Poner en común la } \\
\text { información }\end{array}$ & Puesta en común & $\mathrm{x}$ & $\mathrm{x}$ & $\mathrm{x}$ & \\
\hline & & $\begin{array}{l}\text { Tomar una decisión } \\
\text { justificada, como } \\
\text { miembros de un } \\
\text { claustro, acerca de una } \\
\text { situación relacionada } \\
\text { con la vacunación }\end{array}$ & $\begin{array}{l}\text { Toma de decisión } \\
\text { grupal }\end{array}$ & & & & \\
\hline \multirow[t]{2}{*}{7} & \multirow[t]{2}{*}{37} & $\begin{array}{l}\text { Utilizar lo aprendido } \\
\text { para explicar un } \\
\text { fenómeno relacionado } \\
\text { con la vida cotidiana }\end{array}$ & $\begin{array}{l}\text { Aplicación del } \\
\text { modelo }\end{array}$ & & & $\mathrm{x}$ & \\
\hline & & $\begin{array}{l}\text { Tomar una decisión } \\
\text { justificada, como } \\
\text { padre/madre de } \\
\text { familia, acerca de una } \\
\text { situación relacionada } \\
\text { con la vacunación }\end{array}$ & $\begin{array}{l}\text { Toma de decisión } \\
\text { individual }\end{array}$ & & & $\mathrm{x}$ & $\mathrm{x}$ \\
\hline 8 & 38 & $\begin{array}{l}\text { Expresar } \\
\text { conocimientos y } \\
\text { opiniones }\end{array}$ & Cuestionario 2 & $\begin{array}{c}x \\
(3,5,6,7,8)\end{array}$ & $\begin{array}{l}\mathrm{x} \\
(4)\end{array}$ & $\begin{array}{c}\mathrm{x} \\
(14)\end{array}$ & $\begin{array}{c}\mathrm{x} \\
(11)\end{array}$ \\
\hline
\end{tabular}

\section{Instrumentos y métodos de análisis}

Los objetivos de la investigación y los instrumentos utilizados para la toma de datos para cada uno de ellos se incluyen en la tabla 1.

La primera pregunta de investigación se ha dividido en diferentes partes: a) la concepción sobre las vacunas, $b$ ) la expresión del modelo de sistema inmunológico en el contexto de la vacunación, $c$ ) la expresión del modelo de sistema inmunológico en otros contextos. Los instrumentos utilizados han sido, para las tres partes, respuestas escritas individuales y transcripciones de las discusiones grupales en la puesta en común.

Respecto a la concepción sobre las vacunas, las preguntas cuyas respuestas se han analizado han sido: ¿Qué son las vacunas?; ¿Son eficaces frente a enfermedades causadas por bacterias? ¿Son eficaces frente a enfermedades causadas por virus?, que se hallaban tanto en el cuestionario 1 (anexo 1) como en el cuestionario 2 (anexo 2). En el caso de la pregunta ¿qué son las vacunas?, se han leído todas las respuestas y se ha procedido a establecer categorías según el nivel conceptual mostrado. Cuando en una respuesta aparecían aspectos de diversos niveles, se ha categorizado esta en el nivel más alto. Se ha procedido de la misma manera en el caso de las discusiones de los estudiantes, situando en un nivel a cada grupo.

Respecto a la expresión del modelo de sistema inmunológico en el contexto de la vacunación, se han tenido en cuenta preguntas en las que predomina el factor explicativo, como ¿qué ocurre en tu 
cuerpo cuando te vacunas?, que se halla tanto del cuestionario 1 como del cuestionario 2. Además, fue discutida en la puesta en común. En cuanto a los instrumentos utilizados para caracterizar la expresión del modelo de sistema inmunológico en otros contextos, se han analizado teniendo en cuenta, además de las discusiones grupales de la puesta en común, dos preguntas del cuestionario 1: Explica qué pasa en tu cuerpo cuando se infecta una herida y ¿Por qué no se pasa la varicela más de una vez?, la actividad aplicación del modelo ¿Qué ocurre en tu cuerpo cuando te tatúas? y una del cuestionario 2, Explica cómo trabaja el sistema inmunológico. Se han establecido categorías teniendo en cuenta las respuestas y la integración de los distintos componentes del modelo de ser vivo en relación con el sistema inmunológico. Así, se ha establecido un nivel SI1 que refleja alusiones a los componentes, a la estructura del sistema, un nivel SI2 que incluye menciones a los cambios, a que el cuerpo reacciona produciendo anticuerpos, y, finalmente, un nivel SI3 que incluye alusiones al cuerpo con un sistema que actúa a lo largo del tiempo una vez producidos los anticuerpos.

En la tabla 2 se muestran ejemplos de respuestas en cada categoría. Se han situado en el nivel más alto mostrado tanto las respuestas individuales como las discusiones grupales.

Tabla 2.

Categorías de expresiones del modelo de sistema inmunológico en relación con el modelo de ser vivo

\begin{tabular}{|c|c|c|c|}
\hline Nivel & Descripción & Ejemplos SI en contexto de la vacunación & Ejemplos SI en otros contextos \\
\hline SI3 & $\begin{array}{l}\text { El cuerpo produce anti- } \\
\text { cuerpos y cómo actúan } \\
\text { estos }\end{array}$ & $\begin{array}{l}\text { 5GO1: Una vacuna tiene virus atenuados. } \\
\text { Cuando se introducen en el cuerpo, nues- } \\
\text { tro cuerpo prepara un ataque inmunoló- } \\
\text { gico para destruir el virus, produciendo } \\
\text { anticuerpos específicos. En ese momento } \\
\text { nuestro cuerpo reconocerá ese nuevo virus } \\
\text { y sabrá "cómo eliminarlo». }\end{array}$ & $\begin{array}{l}\text { 2G01: Al introducirse un virus en nues- } \\
\text { tro cuerpo el sistema inmunitario se } \\
\text { pone en marcha, produciendo anticuer- } \\
\text { pos contra el virus y haciendo frente a } \\
\text { la enfermedad. Los anticuerpos atacan } \\
\text { a los virus y producen inmunidad hacia } \\
\text { la enfermedad. Esa inmunidad puede ser } \\
\text { pasajera o permanente. }\end{array}$ \\
\hline SI2 & $\begin{array}{l}\text { El cuerpo produce defen- } \\
\text { sas o anticuerpos }\end{array}$ & $\begin{array}{l}\text { 6GO1: Se producen defensas en el cuerpo } \\
\text { para no coger enfermedades. }\end{array}$ & $\begin{array}{l}\text { 4GA4: Cuando la herida se infecta, nues- } \\
\text { tro cuerpo produce anticuerpos. }\end{array}$ \\
\hline SI1 & El cuerpo posee defensas & $\begin{array}{l}\text { 8GA3: Introducimos en nuestro cuerpo } \\
\text { el virus. De esa manera, en algunas per- } \\
\text { sonas, se producen efectos negativos como } \\
\text { la fiebre. }\end{array}$ & $\begin{array}{l}\text { 9GA3: Cuando tienes una herida abier- } \\
\text { ta y se infecta por cualquier motivo, el } \\
\text { cuerpo envía "defensas" pero a veces no } \\
\text { es suficiente. }\end{array}$ \\
\hline SI0 & $\begin{array}{l}\text { Respuestas incorrectas: } \\
\text { El cuerpo es inerte }\end{array}$ & $\begin{array}{l}\text { 6GA2: Al tomar vacunas introducimos en } \\
\text { nuestro cuerpo anticuerpos y conseguimos } \\
\text { defensas contra ese virus. }\end{array}$ & $\begin{array}{l}\text { 8GA1: Cuando nos hacemos una heri- } \\
\text { da, se introducen bacterias externas que } \\
\text { dañan nuestro cuerpo. Así, cuando una } \\
\text { herida se infecta, para proteger nuestro } \\
\text { cuerpo (para matar a las bacterias) se uti- } \\
\text { lizan sustancias como el agua oxigenada. }\end{array}$ \\
\hline
\end{tabular}

En cuanto a la segunda pregunta de investigación, la caracterización de la competencia argumentativa, se han analizado los argumentos generados en una pregunta de la toma de decisión individual, en la que se explicaban los problemas asociados al virus del papiloma humano y se preguntaba al alumnado si pondrían o no la vacuna a su hija. Para ello, se han analizado las justificaciones que dan para defender la postura adoptada así como de qué manera tienen en cuenta la postura contraria. Se ha realizado el contraste con la postura mostrada frente a las vacunas (cuestionario 1), así como con las ventajas e inconvenientes a los que hacen referencia, al ser preguntados en el cuestionario 1 y en el cuestionario 2 ("¿Qué ventajas y qué desventajas tienen las vacunas?»). 


\section{RESULTADOS}

\section{Modelos de sistema inmunológico en contexto}

\section{El concepto de vacuna y su eficacia}

Las respuestas a la pregunta ¿qué son las vacunas? fueron categorizadas sobre la base de su acercamiento al concepto científico de vacunas (tabla 3), de manera que se establecieron cuatro niveles de respuesta, desde su consideración como meros instrumentos (nivel V1), hasta identificar que sus principales componentes son los antígenos (nivel V4). El nivel V0 corresponde a respuestas incorrectas.

Tabla 3.

Categorías de respuesta del alumnado sobre las vacunas

\begin{tabular}{|c|l|l|}
\hline Nivel & \multicolumn{1}{|c|}{ Descripción } & \multicolumn{1}{c|}{ Ejemplos } \\
\hline Nivel V4 & Las vacunas son antígenos. & $\begin{array}{l}\text { 1GA1: Son antígenos. Concretamente antígenos de } \\
\text { los virus. }\end{array}$ \\
\hline Nivel V3 & $\begin{array}{l}\text { Las vacunas son seres vivos o virus debilitados o la- } \\
\text { tentes. }\end{array}$ & $\begin{array}{l}\text { 7GA1: Son virus pequeños que se introducen en } \\
\text { nuestro cuerpo. }\end{array}$ \\
\hline Nivel V2 & $\begin{array}{l}\text { Las vacunas son tratamientos o medicinas que in- } \\
\text { troducen en el cuerpo para evitar enfermedades }\end{array}$ & $\begin{array}{l}\text { 6GO1: Son medicinas que se introducen en el cuer- } \\
\text { po con una aguja para evitar o amortiguar algunas } \\
\text { enfermedades conocidas. }\end{array}$ \\
\hline Nivel V1 & $\begin{array}{l}\text { Las vacunas son sustancias o instrumentos como las } \\
\text { inyecciones. }\end{array}$ & $\begin{array}{l}\text { 3GO1: Las inyecciones que se utilizan para evitar } \\
\text { las enfermedades que afectan a nuestra salud. }\end{array}$ \\
\hline Nivel V0 & Respuestas incorrectas. & $\begin{array}{l}\text { 2GA4: Inocular de alguna manera en nuestro cuer- } \\
\text { po la enfermedad no agresiva que se quiere evitar. }\end{array}$ \\
\hline
\end{tabular}

En la figura 3 se presenta el porcentaje de estudiantes en cada nivel, en el cuestionario 1 y en el cuestionario 2 .

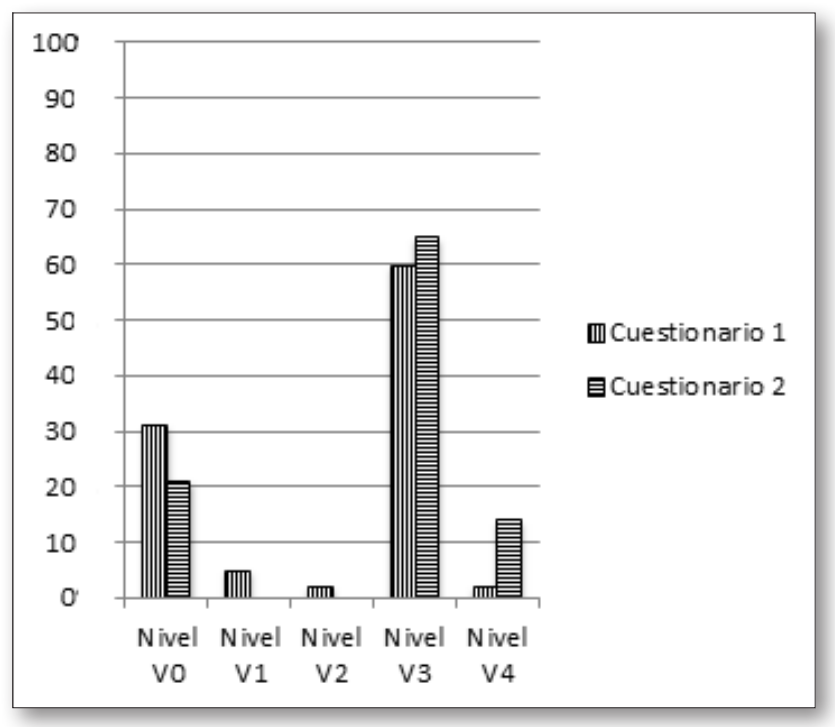

Fig. 3. Ideas iniciales y finales sobre las vacunas (en porcentajes). 
Las respuestas a partir del nivel V3 son las más adecuadas ya que consideran las vacunas como virus atenuados o latentes, partes de virus o antígenos, y aumentan en 17 puntos al final de la secuencia.

Estos datos iniciales y finales se han relacionado con los datos obtenidos durante la puesta en común, en la que los grupos intercambiaban información. Así, de los ocho grupos de los que se tienen datos, cuatro han manejado información del nivel V4 y los otros cuatro del nivel V3. El nivel de la información sobre las vacunas durante la puesta en común ha sido mayor que el nivel de las respuestas al cuestionario 1. Sin embargo, solo cuatro estudiantes de grupos en los que se discutía en el nivel V4 mantienen ese nivel al final de la secuencia. Además, ningún estudiante de los grupos que no llegaban al nivel V4 en el intercambio de información llegó a ese nivel en el cuestionario 2.

Por otro lado, el porcentaje de respuestas incorrectas, tales como relacionar las vacunas con enfermedades, disminuye 10 puntos al final. A pesar de la disminución se puede considerar un porcentaje elevado.

Las respuestas sobre la eficacia de las vacunas frente a bacterias y virus se presentan en la figura 4.

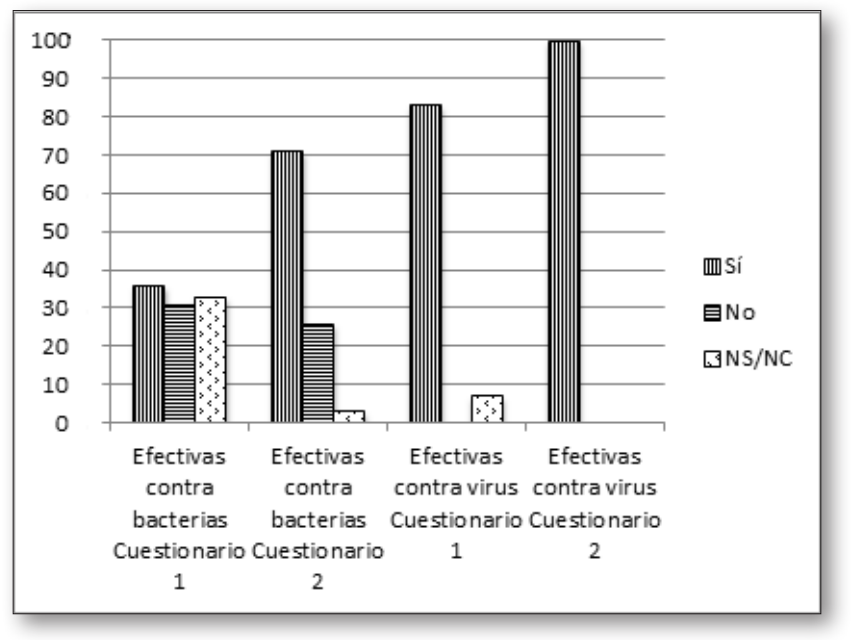

Fig. 4. Ideas iniciales y finales sobre la efectividad de las vacunas frente a las bacterias y los virus (en porcentajes).

El conocimiento de que las vacunas son eficaces frente a las bacterias ha aumentado. También descienden las respuestas codificadas como no sé (NS/NC), de catorce estudiantes al inicio a un solo estudiante al final.

En cuanto a si las vacunas son eficaces frente a los virus, inicialmente el porcentaje de respuestas correctas es alto, y al final se convierte en un $100 \%$. El alumnado que responde de manera incorrecta o no responde desaparece al final de la secuencia.

\section{Modelo de sistema inmunológico en el contexto de la vacunación}

La figura 5 muestra las respuestas obtenidas en el cuestionario inicial (cuestionario 1) y final (cuestionario 2). 


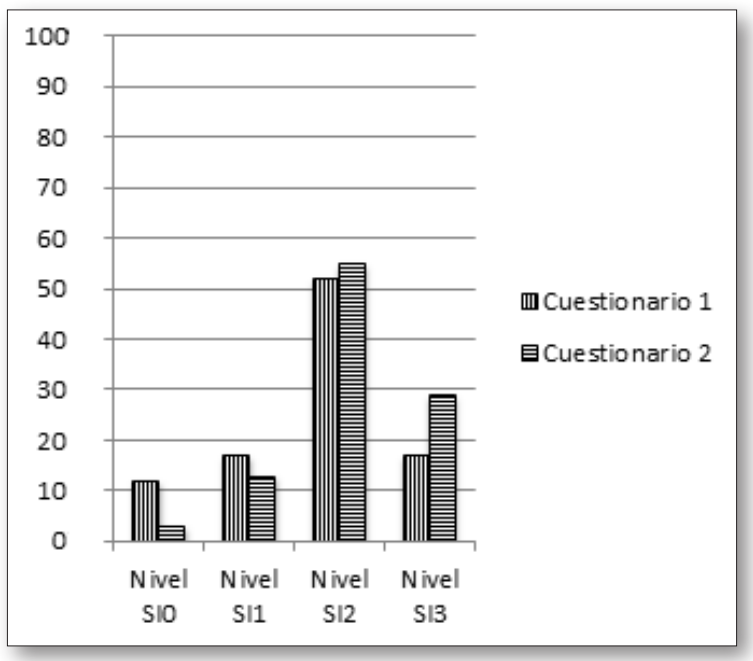

Fig. 5. Niveles del modelo de sistema inmunológico -inicial y final- en el contexto de la vacunación (en porcentajes).

Destaca la diferencia porcentual del nivel SI3, que son las respuestas más adecuadas para explicar el proceso y funcionamiento de las vacunas porque mencionan la introducción de los antígenos, la producción de anticuerpos y su función.

Las respuestas que indican que el cuerpo produce defensas (nivel SI2) aumentan ligeramente al final de la secuencia, destacando que en el $95 \%$ de las respuestas se menciona expresamente la producción de anticuerpos en la respuesta inmunológica. El porcentaje de las respuestas incorrectas en el cuestionario 2 es mínimo.

En el intercambio de información realizado durante la puesta en común, cinco grupos se encuentran en el nivel SI2 y tres en el nivel SI3.

\section{Modelo de sistema inmunológico en distintos contextos}

La figura 6 muestra los resultados obtenidos en las distintas actividades sobre el modelo de sistema inmunológico en función del contexto analizado. El tamaño de los círculos es proporcional al porcentaje de respuestas en cada nivel. Se incluyen los resultados del contexto de vacunación ya analizados para facilitar su comparación con otros.

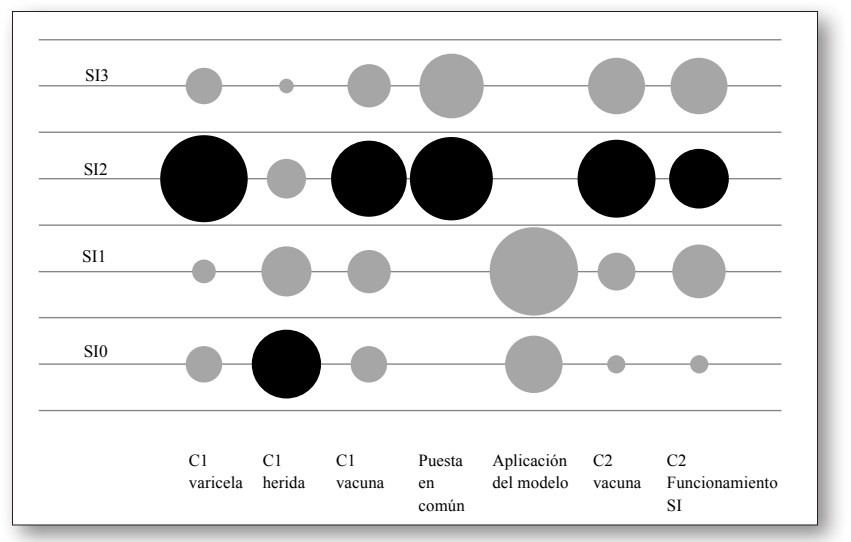

Fig. 6. Niveles del modelo de sistema inmunológico en distintos contextos y momentos. 
Más de la mitad del alumnado (69\%) justifica que una vez pasada la varicela no se vuelve a coger porque el cuerpo tiene anticuerpos. Sin embargo, solo el $12 \%$ del alumnado explica de manera detallada cómo se han producido los anticuerpos y cuál es su función ante una nueva infección.

Casi la mitad del alumnado ( $43 \%$ ) ante una herida infectada considera al cuerpo como un ente inerte. Aunque el $23 \%$ del alumnado responde que ante una infección se pone en marcha el sistema inmunológico, solo una estudiante es capaz de explicar todo el proceso.

En cuanto a las respuestas de aplicación del modelo, se puede decir que el alumnado no relaciona hacerse un tatuaje con la activación del sistema inmunológico. Un estudiante de cada tres considera el cuerpo como un ente inerte. El 57 \% del alumnado solo menciona los cambios morfológicos: inflamación en la zona, aumento de la temperatura...

Durante la puesta en común tres grupos manejan información del nivel SI2 y cinco del nivel SI3. Sin embargo, ante la pregunta del cuestionario 2 sobre el funcionamiento del sistema inmunitario, el $61 \%$ del alumnado menciona la producción de defensas y la formación de anticuerpos (SI2) y once estudiantes explican el proceso completo (SI3). Además, nueve estudiantes disminuyen su nivel de respuesta al final de la secuencia.

\section{Competencia argumentativa}

Se muestra el porcentaje de estudiantes que hacen referencia a cada tipo de ventaja (figura 7) y de desventaja (figura 8).

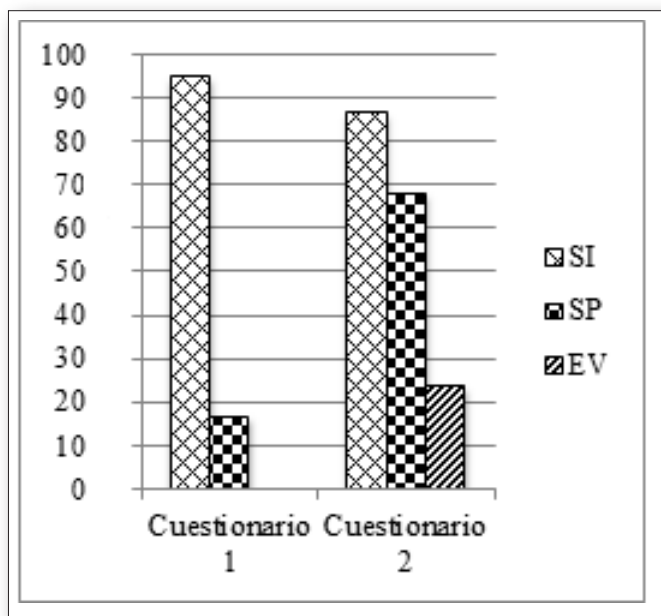

Fig. 7. Porcentaje de estudiantes que mencionan las ventajas de las vacunas (SI: Salud individual; SP: Salud pública; EV: Eficacia de las vacunas).

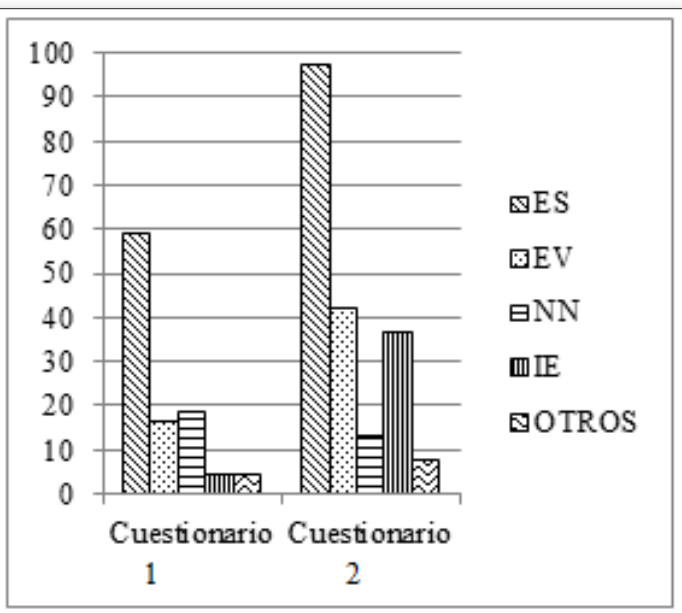

Fig. 8. Porcentaje de estudiantes que mencionan las desventajas de las vacunas (ES: Efectos secundarios; EV: Eficacia de las vacunas; NN: No son naturales; IE: Intereses económicos).

Los estudiantes identifican un tipo de ventaja más en el cuestionario 2. Además, enumeran una media de 1,12 ventajas por persona al inicio y 1,79 posteriormente. En cuanto a las desventajas, inicialmente enumeran una media de 1,05 y finalmente 1,97.

Una vez identificadas las ventajas y las desventajas de las vacunas, se muestran los resultados referentes al posicionamiento frente a las vacunas (cuestionario 1) y con relación a si le pondrían la vacuna contra el virus del papiloma a su hipotética hija (toma de decisión individual). De las 42 personas participantes en el cuestionario 1, 40 de ellas indican estar a favor de las vacunas y 1 en contra. En cuanto a la toma de decisión individual, 25 manifiestan que vacunarían a su hija y 11 que no. En la figura 9 
se muestran todas las categorías utilizadas por las personas que se posicionan en un sentido u otro. Se han tenido en cuenta las utilizadas tanto para las justificaciones como para las limitaciones.

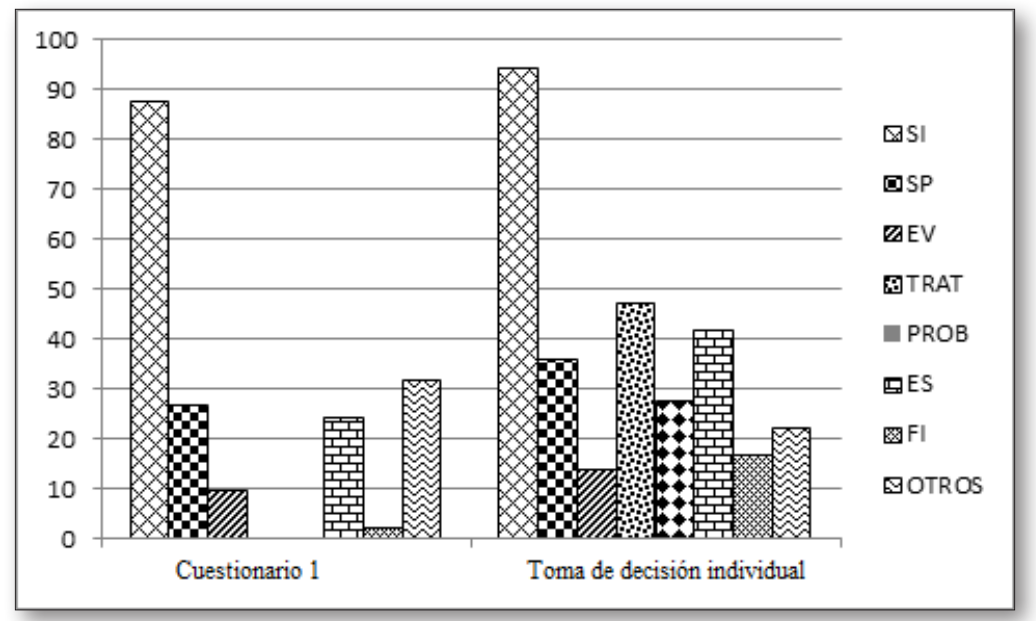

Fig. 9. Categorías de justificaciones y limitaciones empleadas por los estudiantes en su posicionamiento. Se indica el porcentaje de estudiantes que aluden a determinada categoría (SI: Salud individual; SP: Salud pública; EV: Eficacia de las vacunas; TRAT: Tratamientos relacionados con el papiloma; PROB: Probabilidad de padecer la enfermedad; ES: Efectos secundarios; FI: Falta de información).

Tanto las personas que deciden poner la vacuna contra el virus del papiloma humano como las que deciden no ponerla utilizan un mayor número de justificaciones a la hora de defender su posicionamiento en comparación con el número de justificaciones empleadas al explicar el posicionamiento frente a las vacunas en el cuestionario 1. Así, de 1,5 justificaciones por persona iniciales, se ha pasado a 2,08 en el caso de los estudiantes que vacunarían a su hija y a 2,64 en los que no. De la misma manera, aumenta la consideración de las limitaciones de la decisión tomada. Así, de las 0,34 limitaciones mencionadas por persona, se ha pasado a 0,92 en el caso de los estudiantes que vacunarían a su hija y a 0,73 en los que no.

\section{DISCUSIÓN}

Los resultados de este estudio muestran que se ha producido un acercamiento conceptual al modelo de sistema inmunológico del ser vivo y en concreto a la idea clave de intercambio de materia con el entorno en cuanto al concepto de vacuna, su eficacia y su función.

Se observa una mejora, después de realizada la secuencia, en el conocimiento de la composición, el concepto de vacuna y su eficacia frente a virus y bacterias. Así mismo, se da una disminución significativa de respuestas incorrectas, sobre todo las que confunden las enfermedades con sus agentes. Esta confusión puede no ser tan rara si se tiene en cuenta que en el lenguaje coloquial las vacunas son nombradas como la enfermedad que previenen, por ejemplo «vacuna de la gripe». Por otra parte, es interesante comprobar la práctica desaparición de respuestas codificadas como «no sé». Esta evolución y aproximación al modelo de referencia a través de actividades enmarcadas en contextos cotidianos ha sido analizada por Aznar y Puig (2016a, 2016b), en su estudio sobre la tuberculosis. También en dicha investigación los grupos mejoran la comprensión y la utilización adecuada del término vacuna en la fase de revisión del modelo, cuando evalúan su validez para interpretar el fenómeno. El hecho de que ningún estudiante que durante la puesta en común no haya manejado información del nivel V4 haya 
llegado a ese nivel en las respuestas del cuestionario 2, y que el nivel de información haya sido mayor que el de las respuestas del cuestionario 1 supone que el intercambio de información en ese momento de la secuencia es necesario pero no suficiente para que un mayor número de estudiantes se acerque al modelo de referencia.

El hecho de que los resultados sean peores al finalizar la secuencia de lo que lo eran en la puesta en común en los grupos lleva a analizar las posibles causas. Una de ellas puede estar relacionada con la dinámica de la actividad, ya que aunque haya indicios de que se está utilizando información de determinado nivel de complejidad, en la mayoría de los casos se limitan a leer la información, y no muestran evidencias de haberse apropiado de esta, por lo que la actividad se debería haber diseñado de manera que los estudiantes se vieran impelidos a comprender la información que estaban recibiendo y no se limitaran a escucharla. En este caso, se han limitado a hacer lo que se les pedía, a intercambiarla, lo que puede limitar la actividad y el nivel de complejidad que muestran (Kelly y Takao, 2002). En el intercambio de información no se ha propiciado el diálogo interactivo-dialógico (Scott, Mortimer y Aguiar, 2006) en los integrantes de los grupos. Además, la profesora no interviene en ninguna ocasión en ninguno de los grupos para regular el proceso de puesta en común.

Los resultados obtenidos sobre la expresión del modelo de sistema inmunológico en distintos contextos son diferentes en función de la cercanía o lejanía del contexto con el tema tratado. Así, muestran un ligero avance en su comprensión y explicación (véase figura 6), cuando se plantean contextos muy cercanos, como el de la vacunación, en el que los avances pueden relacionarse con asumir la idea clave interacción del modelo de ser vivo, comprender los cambios que se producen a lo largo del tiempo con la vacunación, la respuesta inmunológica y la producción de anticuerpos y su función futura. Este avance está en sintonía con la propuesta de Andrade et al. (2016) de considerar que el sistema inmunológico opera en el mantenimiento de la estructura y organización del cuerpo -ser vivo- a través del equilibrio metabólico dinámico. En este caso, la búsqueda y el intercambio de información han favorecido que el alumnado se acerque al modelo de referencia. En el otro contexto cercano, la pregunta general sobre el funcionamiento del sistema inmunológico, los resultados señalan un nivel de transferencia aceptable por parte del $61 \%$ del alumnado, que se sitúa entre los niveles SI2 y SI3. Sin embargo, los datos de las transcripciones de las grabaciones seńalan que en cinco de los ochos grupos las informaciones intercambiadas se han situado en el nivel SI3 y el resto en el nivel SI2, por lo que la transferencia no ha sido completa.

En cuanto a la cuestión ¿qué ocurre en tu cuerpo cuando te tatúas? (aplicación del modelo), que requería una transferencia más lejana, si bien las respuestas incorrectas descienden un $13 \%$, respecto a la cuestión Explica qué pasa en tu cuerpo cuando se infecta una herida (cuestionario 1), la transferencia es muy pobre. El máximo nivel de desempeño durante la transferencia es de SI1, es decir, se asume que el cuerpo posee defensas, pero los estudiantes no señalan activación del sistema inmunológico. Sadler, Romine y Topçu (2016) también estudiaron cómo era la ganancia conceptual de los estudiantes tras trabajar cuestiones sociocientíficas y observaron que los resultados eran menores en la evaluación lejana que en la cercana, $y$, aunque en su caso incluso en la lejana la ganancia fue significativa, hicieron referencia a estudios anteriores que no hallaron ganancias significativas en el caso de evaluaciones lejanas.

Los resultados sobre el desempeño de la competencia argumentativa han sido positivos. Se ha constatado que en la actividad de integración, en la toma de decisión individual, los estudiantes tienen en cuenta más aspectos relacionados tanto con las ventajas como con las desventajas de las vacunas para posicionarse. Esto se traduce en que utilizan más justificaciones para respaldar la opción que escogen, lo que es un indicador de calidad en los argumentos. Es más, también, han demostrado una mejoría en el aspecto que es considerado más difícil y que indica una alta calidad de la argumentación (Erduran et al., 2004; García-Milá et al., 2013), la consideración de limitaciones de la opción escogida. En este caso, se ha pasado de que un $31,7 \%$ de los estudiantes expliciten limitaciones de su opción a que lo 
hagan un 69,4\%. La consideración de los efectos secundarios es relativamente alta, lo que coincide con lo observado por Lundström et al. (2012), y aumenta a lo largo de la secuencia.

\section{CONCLUSIÓN}

Como conclusión, puede decirse que el trabajo confirma la potencialidad del uso de cuestiones sociocientíficas en el aula para el desarrollo de la competencia argumentativa de los estudiantes en la toma de decisiones, pero que no lo hace de la misma manera en el caso de la comprensión del modelo de sistema inmunológico dentro del modelo de ser vivo, sobre todo dependiendo del contexto de transferencia. En este sentido las autoras trabajan en la mejora de la secuencia para su siguiente implementación.

Consideramos que es interesante mantener el contexto de transferencia lejana del modelo construido, a pesar de los resultados. Los resultados han mostrado una gran dificultad para transferir lo aprendido pero pensamos que el problema radica en el diseño de la secuencia y la forma de aplicarla. Otros autores (Hiebert y Grouws, 2007) ya han demostrado la relación de las oportunidades de aprendizaje que la persona docente crea en el aula con los buenos resultados de transferencia. Un proceso de construcción del modelo adecuado debería permitir que los estudiantes apliquen de forma correcta el modelo en una situación diferente a la de aprendizaje aunque sea muy distinta.

Partiendo de lo observado en este trabajo, pensamos que los puntos más débiles han sido dos. Por una parte, los estudiantes no han profundizado en la información, la han intercambiado pero no ha sido discutida, trabajada ni interiorizada, y muchos estudiantes no la han convertido en conocimiento. Por otra parte, no han extraído del conocimiento sobre el funcionamiento de las vacunas los aspectos del modelo generalizables a otros contextos.

Para tratar de mejorar estos aspectos, se facilitará que los estudiantes tengan acceso a una variedad de contextos en su proceso de construcción del modelo, lo que permitirá establecer similitudes entre ellos (Bransford y Schwartz, 1999) y extraer de esta manera los aspectos generalizables del modelo facilitando la transferencia (Carpintero, 2002).

En este proceso de abstracción, el rol del profesorado es clave, tal y como observaron Schalk, van der Schee y Boersma (2013). En la investigación que llevaron a cabo, los estudiantes en la mayoría de los casos solo llegaban a realizar generalizaciones y explicaciones en el proceso de apropiación de criterios de calidad de una investigación con la ayuda del profesor y, sin su presencia, se quedaban en el nivel de las descripciones. En este caso, por lo tanto, es necesario un rol activo, de tal manera que plantee explícitamente a los estudiantes la tarea de establecer semejanzas y les ayude en este proceso.

Además, para que el intercambio de información tenga un fin, un sentido para el alumnado, se propondrá que construyan grupalmente maquetas explicativas de los elementos y procesos implicados en los diversos contextos. El proceso de construir la maqueta que represente la información llevará a los estudiantes a tomar decisiones basadas en dicha información, a plantearse dudas que la lectura no había planteado, por lo que puede convertirse en una oportunidad de aprendizaje.

\section{AGRADECIMIENTOS}

$\mathrm{Al}$ proyecto de investigación EHU15/25, financiado por la UPV/EHU, del que forma parte este trabajo. Al alumnado que participó en la investigación. 


\section{REFERENCIAS BIBLIOGRÁFICAS}

AEP-Asociación Española de Pediatría (2016). Pronunciamiento europeo contra el rechazo a las vacunas. Disponible en línea: <http://vacunasaep.org/familias/noticias/pronunciamiento-europeo-contrael-rechazo-a-vacunas>.

Andrade, V. A., Araújo-Jorge, T. C. y Coutinho-Silva, R. (2016). Concepçöes discentes sobre inmunologia e sistema immune humano. Investigaçôes em Ensino de Ciências, 21 (3), 1-22. https://doi.org/10.22600/1518-8795.ienci2016v21n3p1

Aznar, V. y Puig, B. (2016a). Concepciones y modelos del profesorado de primaria en formación acerca de la tuberculosis. Enseñanza de las Ciencias, 34(1), 33-52. https://doi.org/10.5565/rev/ensciencias. 1670

Aznar, V. y Puig, B. (2016b). ¿Qué conocimientos movilizan un grupo de futuros docentes para elaborar el modelo de infección por tuberculosis? Revista Eureka sobre Enseñanza y Divulgación de las Ciencias, 13(2), 264-278.

Barnett, S. M. y Ceci, S. J. (2002). When and where do we apply what we learn? A taxonomy for far transfer. Psychological Bulletin, 128(4), 612-637. https://doi.org/10.1037//0033-2909.128.4.612

BOE (2014). Real Decreto 126/2014, de 28 de febrero, por el que se establece el currículo básico de la Educación Primaria. Disponible en línea: <https://www.boe.es/boe/dias/2014/03/01/pdfs/BOEA-2014-2222.pdf>.

Bransford, J. D. y Schwartz, D. L. (1999). Rethinking transfer: A simple proposal with multiple implications. Review of Research in Education, 24(3), 61-100.

https://doi.org/10.2307/1167267

https://doi.org/10.3102/0091732X024001061

Carpintero, E. (2002). El proceso de transfer: Revisión y nuevas perspectivas. EduPsykhé: Revista De Psicología y Psicopedagoía, 1(1), 69-96.

COSCE (2011). Informe ENCIENDE. Enseñanza de las Ciencias en la Didáctica escolar para edades tempranas en España. Madrid. Disponible en línea: <http://www.cosce.org/pdf/Informe_ENCIENDE. pdf>.

Díaz, N. y Jiménez-Liso, M. R. (2012). Las controversias sociocientíficas: Temáticas e importancia para la educación científica. Revista Eureka sobre Enseñanza y Divulgación de las Ciencias, 9(1), 54-70.

Erduran, S., Simon S. y Osborne J. (2004). TAPping into argumentation: Developments in the application of Toulmin's Argument Pattern for studying science discourse. Science Education, 88(6), $915-$ 933. https://doi.org/10.1002/sce.20012

Erickson, F. (1989). Métodos cualitativos de investigación sobre la enseñanza. En M. Wittrock (Ed.), La investigación de la enseñanza, II. Métodos cualitativos y de observación (pp. 195-301). Barcelona: Paidós.

Felton, M., García-Milá, M. y Gilabert, S. (2009). Deliberation versus dispute: The impact of argumentative discourse goals on learning and reasoning in the science classroom. Informal Logic, 29(4), 417-446. https://doi.org/10.22329/il.v29i4.2907

García-Milá, M., Gilabert, S., Erduran, S. y Felton, M. (2013). The effect of argumentative task goal on the quality of argumentative discourse. Science Education, 97(4), 497-523. https://doi.org/10.1002/sce.21057

GeE, J. P. (1999). An introduction to discourse analysis: Theory and method. Londres: Routledge. 
Goldstone, R. L. y DAY, S. B. (2012). Introduction to «new conceptualizations of transfer of learning». Educational Psychologist, 47(3), 149-152.

https://doi.org/10.1080/00461520.2012.695710

Hiebert, J. y Grouws, D. A. (2007). The effects of classroom mathematics teaching on students' learning. In F. K. Lester (Ed.), Second handbook of research on mathematics teaching and learning (pp. 371404). Charlotte, NC: Information Age Publishers.

Hmelo-Silver, C. E. y Barrows, H. S. (2008). Facilitating collaborative knowledge building. Cognition and Instruction, 26, 48-94. https://doi.org/10.1080/07370000701798495

Jiménez-Aleixandre, M. P. (2010). 10 ideas clave. Competencias en argumentación y uso de pruebas. Barcelona: Graó.

JimÉNEZ-AleXANDRE, M. P. (2012). Las prácticas científicas en la investigación y en el aula de ciencias. Conferencia plenaria. XXV Encuentros de Didáctica de las Ciencias Experimentales, 9-14. Disponible en línea: <http://www.apice-dce.com/sites/default/files/XXV\%20EDCE.pdf>.

JimÉnez-Aleixandre, M. P., Sanmartí, N. y Couso, D. (2011). Reflexiones sobre la ciencia en edad temprana en España: la perspectiva de la enseñanza de las ciencias. In COSCE, Informe ENCIENDE. Enseñanza de las Ciencias en la Didáctica escolar para edades tempranas en España (pp. 57-74). Disponible en línea: <http://www.cosce.org/pdf/Informe_ENCIENDE.pdf>.

Justi, R. (2006). La enseñanza de ciencias basada en la elaboración de modelos. Enseñanza de las Ciencias, 24(2), 173-184.

KelLy, G. J. y TAKAO, A. (2002). Epistemic levels in argument: An analysis of university oceanography students' use of evidence in writing. Science Education, 86, 314-342. https://doi.org/10.1002/sce.10024

Kortland, K. (1996). An STS Case Study about Students'Decision Making on the Waste Issue. Science Education, 80(6), 673-689. https://doi.org/10.1002/(SICI)1098-237X(199611)80:6<673::AID-SCE3>3.0.CO;2-G

Lовато, J. (2012). The actor-oriented transfer perspective and its contributions to educational research and practice. Educational Psychologist, 47(3), 232-247. https://doi.org/10.1080/00461520.2012.693353

Lundström, M., Ekborg, M. y Ideland, M. (2012). To vaccinate or not to vaccinate: how teenagers justified their decision. Cultural Studies of Science Education, 7, 193-221. https://doi.org/10.1007/s11422-012-9384-4

McClune, B. y Jarman, R. (2014). Promoting science literacy via science journalism: Issues and challenges. En L. Tan Wee Hin y R. Subramaniam (Eds.), Communicating science to the public (pp. 3-20). Dordrecht: Springer. https://doi.org/10.1007/978-94-017-9097-0_1

McIntosh, E. D. G., Janda, J., Ehrich, J. H. H., Pettoello-Mantovani, M. y Somekh, E. (2016). Vaccine Hesitancy and Refusal. The Journal of Pediatrics, 175, 248-249.e1. Disponible en línea: <http://www.jpeds.com/article/S0022-3476(16)30366-3/pdfs. https://doi.org/10.1016/j.jpeds.2016.06.006

MendonçA, P. C. C. y Justi, R. (2014). An instrument for analyzing arguments produced in modelingbased chemistry lessons. Journal of Research in Science Teaching, 51(2), 192-218. https://doi.org/10.1002/tea.21133

Merino, G., Felipe, A. E. y Gallarreta, S. C. (2005). La modelización en la enseñanza de la biología del desarrollo. REEC: Revista Electrónica de Enseñanza de las Ciencias, 4 (3). Disponible en línea: $<$ http://reec.uvigo.es/volumenes/volumen4/ART5_Vol4_N3.pdf>. 
Mouzo, J. (2015). Muere el niño de seis años enfermo de difteria en Olot. El País. Disponible en línea: $<$ http://ccaa.elpais.com/ccaa/2015/06/27/catalunya/1435393852_158995.html>.

MSSSI-Ministerio de Sanidad, Servicios Sociales e Igualdad (2016). Programa de vacunaciones. Disponible en línea: <http://www.msssi.gob.es/ciudadanos/proteccionSalud/infancia/vacunaciones/ home.htm>.

Pigrau, T. y Sanmartí, N. (2015). Model per interpretar sistemes vius. Disponible en línea: <http://media. wix.com/ugd/81d0d8_2bd060dd60e84ba88ed018a28dc03fe6.pdf>.

Roorda, G., Vos, P. y Goedhart, M. J. (2015). An Actor-Oriented Transfer perspective on high school students'development of the use of procedures to solve problems on rate of change. International Journal of Science and Mathematics Education, 13(4), 863-889. https://doi.org/10.1007/s10763-013-9501-1

Sadler, T. D., Romine, W. L. y Topçu, M. S. (2016). Learning science content through socio-scientific issues-based instruction: a multi-level assessment study. International Journal of Science Education, 38(10), 1622-1635. https://doi.org/10.1080/09500693.2016.1204481

SAdler, T. D. y Zeidler, D. L. (2005). Patterns of Informal Reasoning in the Context of Socioscientific Decision Making. Journal of Research in Science Teaching, 42(1), 112-128. https://doi.org/10.1002/tea.20042

Schalk, H. H., Van Der Schee, J. A. y Boersma, K. Th. (2013). The development of understanding of evidence in pre-university biology education in the Netherlands. Research in Science Education, 43, 551-578. https://doi.org/10.1007/s11165-011-9276-8

Schwarz, C. V., Reiser, B. J., Davis, E. A., Kenyon, L., Achér, A., Fortus, D., Shwartz, Y., Hug, B. y KrAJCIK, J. (2009). Developing a learning progression for scientific modeling: Making scientific modeling accessible and meaningful for learners. Journal of Research in Science Teaching, 46(6), 632654. https://doi.org/10.1002/tea.20311

Scott, P., Mortimer, E. y Aguiar, O. (2006). The tension between authoritative and dialogic discourse: a fundamental characteristic of meaning making interactions in high school science lessons. Science Education, 90(4), 605-631.

https://doi.org/10.1002/sce.20131 


\section{ANEXO 1}

\section{Cuestionario 1}

\section{NOMBRE-APELLIDOS:}

1.- Explica qué pasa en tu cuerpo cuando se infecta una herida.

2.- ¿Por qué una vez pasada la varicela no se vuelve a pasar otra vez?

3.- ¿Qué son las vacunas?

4.- Explica qué ocurre en nuestro cuerpo cuando nos vacunamos.

5.- ¿Las vacunas son eficaces frente a enfermedades causadas por bacterias?

$$
\text { Sí No No sé }
$$

6.- ¿Las vacunas son eficaces frente a enfermedades causadas por virus?

$$
\text { Sí No No sé }
$$

7.- ¿La inmunización producida por las vacunas se mantiene toda la vida?

$$
\text { Sí No No sé }
$$

8.- ¿Las vacunas siempre contienen un pequeño número de organismos de la enfermedad que producen?

$$
\text { Sí No No sé }
$$

9.- Nombra las vacunas que hoy en día ofrece Osakidetza.

10.-Nombra las vacunas que has recibido

11.- Enumera las ventajas y desventajas de la vacunación.

$$
\text { Ventajas Desventajas }
$$

12.- ¿Estás a favor o en contra de la vacunación? Justifica tu respuesta.

13.- Hoy día las familias deciden sobre si poner o no las vacunas recomendadas por Osakidetza. En tu opinión, debería seguir siendo así o se debería obligar. Justifica tu respuesta. 


\section{ANEXO 2}

\section{Cuestionario 2}

\section{NOMBRE-APELLIDOS:}

3.- ¿Qué son las vacunas?

4.- Explica qué ocurre en nuestro cuerpo cuando nos vacunamos.

\begin{tabular}{|l|l|l|l|}
\hline $\begin{array}{l}\text { 5.- ¿Las vacunas son eficaces frente a las enfermedades causadas por } \\
\text { las bacterias? }\end{array}$ & & & No sé \\
\hline $\begin{array}{l}\text { 6.- ¿Las vacunas son eficaces frente a las enfermedades causadas por } \\
\text { los virus? }\end{array}$ & & & \\
\hline $\begin{array}{l}\text { 7.- ¿La inmunización producida por las vacunas se mantiene toda la } \\
\text { vida? }\end{array}$ & & \\
\hline $\begin{array}{l}\text { 8.- ¿Las vacunas siempre contienen un pequeño número de } \\
\text { organismos de la enfermedad que producen? }\end{array}$ & & \\
\hline
\end{tabular}

11.- Enumera las ventajas y desventajas de la vacunación.

Ventajas

$$
\mid
$$

14.- Explica cómo trabaja el sistema inmunológico.
Desventajas 


\section{Modelling, argumentation and knowledge transfer of preservice teachers about the immune system on a controversy about vaccination}

\author{
Gurutze Maguregi González, Araitz Uskola Ibarluzea \\ Departamento de Didáctica de la Matemática y las Ciencias \\ Experimentales. Universidad del País Vasco/ Euskal Herriko \\ Unibertsitatea- UPV/EHU \\ gurutze.maguregi@ehu.eus, araitz.uskola@ehu.eus
}

\author{
Begoña Burgoa Etxaburu \\ ISEI-IVEI (Instituto de Evaluación e Investigación \\ Educativa); grupo LIEC (UAB) \\ bbetxaburu@gmail.com
}

The objective of this research is to analyse, on the one hand, the construction of the model of immune system, which is included in the model of living beings, and, on the other, the development of the ability for argumentation, of 42 Elementary preservice teachers that took part in a teaching sequence based on a socioscientific controversy about vaccination.

A sequence of activities has been designed purposely. Initially, the students expressed their knowledge about the immune system and vaccination, and their positioning about the latest. Then they formulated questions and searched for information, which they later shared. Several final activities were performed by the students, who, in some of them, had to apply the constructed scientific knowledge in similar (near transfer) and different contexts (far transfer), and in others had to make a justified decision in a socioscientific context about vaccination.

To characterize the model of the immune system constructed by the students, their written answers to the initial and final questionnaires and the oral discussions during the information-sharing have been studied. Specifically, the questions were about the concept and effectiveness of vaccines, and on the model of immune system in several contexts including vaccination. Levels of complexity were established taking into account the responses of the students and the characteristics of the model of immune system they reflected.

Regarding the development of the ability for argumentation, the number and type of advantages and disadvantages expressed by students initially and finally, and the justification of the initial and final positioning have been taken into account. The initial positioning was about the vaccination, and in the final one was they had to decide whether they would put HPV vaccine on their daughter.

The results show that, after the sequence, the model of immune system of the students has improved, especially referring to the key idea of matter exchange with the environment, to the concept, effectiveness and function of vaccines.

However, the results about the expression of the model of immune system in the contexts for transfer have been different depending on the closeness of the transfer context to the context used during the learning sequence. Indeed, the results show an improvement in near contexts, such as vaccination, but when the context is a far one, as in the case of the tattoo, the transferring is poor.

Regarding the ability for argumentation, the results show that, at the end of the learning sequence, the students have taken into account more advantages and disadvantages of the vaccination to justify their positioning about it. In this way their arguments show better justifications and also the limitations of their decisions, in line with higher level of argumentation quality.

As a conclusion, the research confirms the potentiality of the use of socioscientific issues in science classes to develop the ability for argumentation of the students in their decision makings. However, the same cannot be said for the conceptual knowledge construction, as the improvement has been lesser than expected and highly depending on the transfer context.

So as to improve the results in future interventions, it is considered necessary to make changes in the activities and to reconsider the role of the teacher. We think that to facilitate the generalization of the model and its later transfer, the changes should be to give the chance to the students to work through a variety of contexts during the construction of the model, and to include the construction of explanatory physical models in each of them. In the process of abstraction, the role of the teacher is key, and he or she should explicitly ask the students to establish similarities among the contexts, helping them to make the necessary generalizations. 